\title{
(2) OPEN ACCESS \\ Concurrent BK polyomavirus, adenovirus and cytomegalovirus infections in a patient treated for chronic lymphocytic leukaemia
}

\author{
Michelle Kwok, ${ }^{1}$ John Lin, ${ }^{2}$ Jean-Pierre Routy ${ }^{2,3}$
}

'Division of Internal Medicine, McGill University Health Centre, Montréal, Quebec, Canada ${ }^{2}$ Infectious Disease and Immunity in Global Health Program, Research Institute of the McGill University Health Centre, Montréal, Quebec, Canada

${ }^{3}$ Division of Haematology, McGill University Health Centre, Montreal, Quebec, Canada

Correspondence to Dr Jean-Pierre Routy; jean-pierre.routy@mcgill.ca

Accepted 16 November 2020

Check for updates

(C) BMJ Publishing Group Limited 2020. Re-use permitted under CC BY-NC. No commercial re-use. See rights and permissions. Published by BMJ.

To cite: Kwok M, Lin J, Routy J-P. BMJ Case

Rep 2021;14:e235981.

doi:10.1136/bcr-2020-

235981

\section{SUMMARY}

A 58-year-old woman with chronic lymphocytic leukaemia (CLL) presented with 2 weeks of fever and haematuria following chemo-immunotherapy. CT scan showed thickening of her left urethra and bladder, suggesting pyleo-ureteritis with cystitis. The patient was initially treated for suspected bacterial urinary tract infection although repeated blood and urine cultures remained negative. She then received multiple transfusions for chemotherapy-induced pancytopenia while her urinary symptoms did not improve. Due to her immunocompromised status, she was tested for viral infection, which revealed, BK polyomavirus, adenovirus and cytomegalovirus in serum and urine. Cidofovir was initially administered to treat these infections while ganciclovir was used with filgrastim due to neutropenia. The patient subsequently improved. This case represents a diagnostic and therapeutic challenge due to the multiple concurrent viral infections causing haematuria as well as the combined post-chemo-immunotherapy and antiviral myelotoxicity in a CLL patient.

\section{BACKGROUND}

Chronic lymphocytic leukaemia (CLL) is a lymphoproliferative disorder associated with mature B-cell dysfunction, hypogammaglobulinaemia and T-cell abnormalities. In Europe and North America, CLL is the most common leukaemia, with median age of diagnosis of 70 years. ${ }^{1}$ Treatment is indicated only for symptomatic disease, such as anaemia $<100 \mathrm{~g} / \mathrm{L}$ and/or thrombocytopenia $<100 \times 10^{9} / \mathrm{L}$, massive splenomegaly, lymphadenopathy or constitutional symptoms. ${ }^{2}$

Infection is a frequent cause of morbidity and mortality in CLL. Roughly $30 \%-50 \%$ of all CLL patients suffer infections, with a high subsequent mortality rate. ${ }^{3}$ While the majority of infections affect more often the respiratory track, or skin and the gastrointestinal tract. ${ }^{4}$ The most frequent organisms causing infections are bacteria like Streptococcus pneumoniae, Staphylococcus aureus, Streptococcus pyogenes and Escherichia coli. This increased susceptibility to infection stems from B-cells with impaired immunoglobulin production capability and dysfunctional T-helper cells, which also assist in antibody production. This impaired capability to produce immunoglobulins, termed hypogammaglobulinaemia, affects $85 \%$ of CLL patients, particularly in advanced disease. ${ }^{4}$

Antineoplastic agents recommended for the treatment of CLL are also immunosuppressive

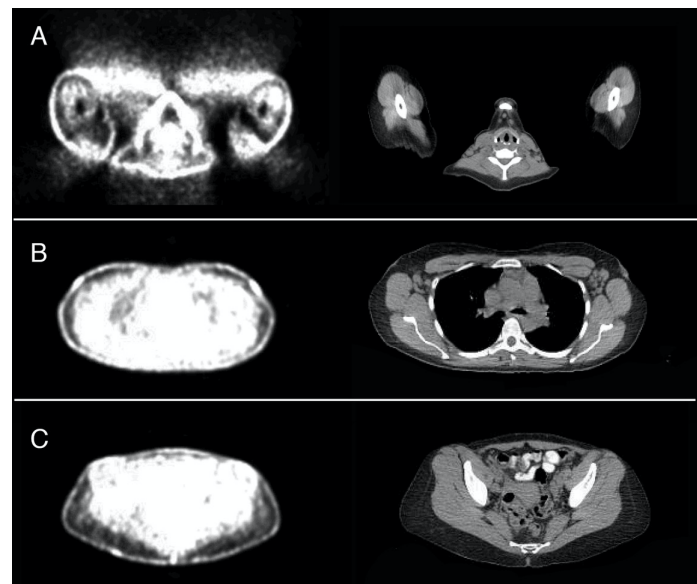

Figure 1 Positron emission tomography scan (right) and corresponding CT images (left) of multiple lowgrade hypermetabolic lymph nodes in 2017, 2 years after diagnosis of chronic lymphocytic leukaemia. (A) Multiple small low-grade hypermetabolic lymph nodes in bilateral neck regions predominantly in the posterior triangles. SUV of 1.9 in the left and right upper posterior triangles. (B) Hypermetabolic lymph nodes in the left axillary regions, SUV 1.8. (C) Left external iliac lymph node SUV of 3. SUV, Standardized uptake value.

and further increase the risk of infections. ${ }^{5}$ These include opportunistic micro-organisms such as Candida, Pneumocystis jirovecii, listeria, nocardia and atypical mycobacteria. In addition, patients have increased risk of viral diseases such as herpes simplex, Epstein-Barr and cytomegalovirus (CMV). Additional infectious complications may include hepatitis $B$ reactivation and progressive multifocal

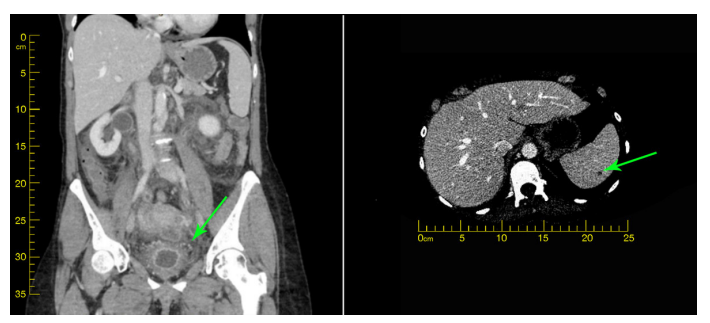

Figure 2 CT urogram on admission in November 2019, demonstrating (A) poorly distended bladder and marked thickening of bladder walls (green arrow) and (B) moderate dilation of both ureters and collection ducts with marked thickening and enhancement of the urothelium associated with moderate periureteric fat stranding. 


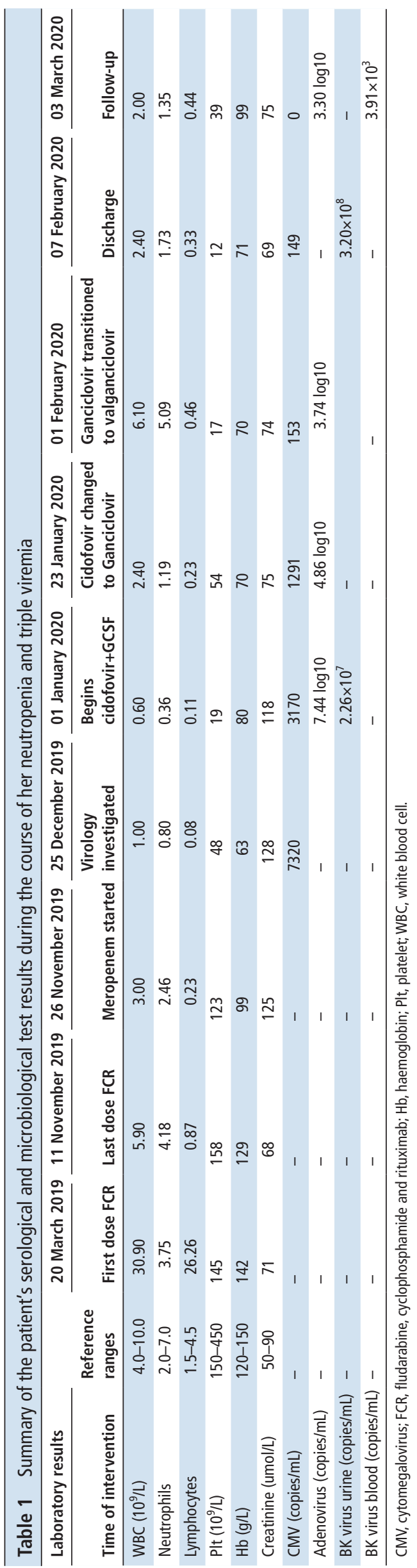

leucoencephalopathy. In spite of the immunosuppressive risk, chemo-immunotherapy with fludarabine, cyclophosphamide and rituximab (FCR) remains the standard risk therapy in fit patients below 65 years of age with CLL, in absence of $17 p$ deletion, or TP53 mutation, and with immunoglobulin heavy chain V (IGHV)-mutated. ${ }^{6}$

To reduce risk of infection, immunoglobulin levels should also be routinely monitored, particularly with rituximab, which reduces the number of B-cells expressing CD20. It is postulated that monitoring immunoglobulins while being treated with rituximab may reduce the risk of serious infections. ${ }^{4}$

Herein, we present a unique case of a woman treated for CLL who experienced severe pancytopenia and immunosuppression at the completion of her chemo-immunotherapy. She subsequently experienced triple concurrent viral infections, which posed a therapeutic challenge due to her pancytopenia.

\section{CASE PRESENTATION}

A previously healthy 58 -year-old woman was diagnosed with CLL through a routine blood test in 2015. Her physical examination was unremarkable and her lymphocyte counts were at $12.36 \times 10^{9} \mathrm{cells} / \mathrm{L}$. Bone marrow biopsy with immunohistochemistry was suggestive of CLL and stained positive for BCL2, CD5 (aberrant T-cell marker), CD20, CD23, CD43 and CD79a (B-cell markers) while BCL6 was negative. The PCR amplification study showed immunoglobulin heavy chain gene rearrangement along with IgG kappa light chain gene arrangement. No $\mathrm{t}(14 ; 18) \mathrm{BCL} 2 / \mathrm{JH}$ or $\mathrm{t}(11 ; 14) \mathrm{BCL} 1 / \mathrm{JH}$ gene rearrangements were observed. As she was asymptomatic, and positron emission tomography (PET) scan showed low grade metabolic activity in lymph nodes in cervical, axillary and iliac areas, no therapy was initiated (figure 1). She was followed every 6 months.

In November 2017 the patient had symptom of a rapid bilateral enlargement of the cervical lymph nodes accompanied by persistent fatigue, night sweats and decreased weight. Lyme disease, HIV, hepatitis B and C and syphilis serologies were performed, and all tests yielded negative results. Repeat PET/ CT scan, cytogenetics and bone marrow biopsy demonstrated no evidence of Richter's transformation into a diffuse large cell lymphoma. Due to significant bulky disease and enlarged adenopathy with B constitutional symptoms, chemo-immunotherapy with FCR was considered. This was furthermore rationalised as she was a fit patient younger than 65 years of age with standard risk for CLL due to the absence of $17 \mathrm{p}$ deletion, or TP53 mutation, and with IGHV being mutated.'

She received six cycles of FCR which was completed uneventfully on 11 November 2019. During FCR therapy, she received oral valacyclovir $500 \mathrm{mg}$ two times per day for herpes prophylaxis as well as Septra DS $(160 \mathrm{mg}$ trimethoprim and $800 \mathrm{mg}$ sulfamethoxazole) one tablet Mondays, Wednesdays and Fridays for P. jirovecii prophylaxis. On 18 November, she presented to the emergency room of the McGill University Health Centre (MUHC) with haematuria, suprapubic pain and fever. She was admitted and treated for a urine infection and slowly improved after different antibiotics such as ciprofloxacin, trimethoprimsulfamethoxazole and ceftriaxone and blood and urinary bacterial cultures were negative. A CT urogram showed moderate bilateral hydroureteronephrosis with diffuse urolithelial and bladder thickening (figure 2). As a whole, these findings were suggestive of an inflammatory or infectious process evoking pyleoureteritis and cystitis. 
A

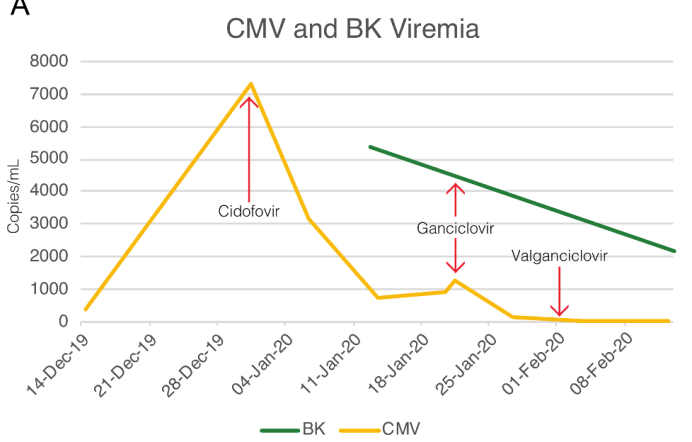

B

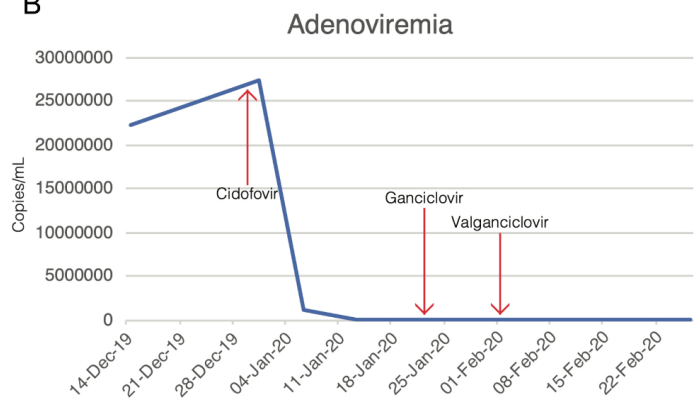

Figure 3 Cytomegalovirus (CMV) and BK viremia (A) and adeno-viremia (B) over the course of treatment.

\section{INVESTIGATIONS}

On admission, she was mildly pancytopenic (table 1). As the patient partially improved and had negative urine cultures, a cyclophosphamide-induced haemorrhagic cystitis was considered, and she was placed on continuous bladder irrigation.

On 1 December 2019 she developed a pancytopenia that required platelet and packed red blood cell transfusions. She remained persistently febrile despite repeated negative bacterial blood and urine cultures. Due to her CLL, pancytopenia and the consideration of immunosuppression induced by FCR chemotherapy, viral infections were investigated. PCR for adenovirus showed 22.4 copies $/ \mathrm{mL}$ in blood, and positive in urine; PCR for polyoma virus showed 8.81 million copies $/ \mathrm{mL}$ blood; and PCR for CMV showed 358 copies $/ \mathrm{mL}$ in blood, confirming viral invasive infections (figure 3). To further investigate her pancytopenia, serology for parvovirus B 19 was carried out and was negative for IgM.

On 18 December 2019 the patient underwent a double J-stent insertion for bilateral hydronephrosis. Pelvic pain persisted and she continued to pass clots in her urine. Repeat CMV PCR testing on 25 December 2019 showed 7320 copies/mL while an ophthalmological assessment revealed no evidence of CMV retinitis or keratitis. Bone marrow biopsy results showed pancytopenia without transformation (figure 4).

\section{TREATMENT}

On 1 January 2020, cidofovir was administered to treat the three viral infections of BK polyomavirus, adenovirus and CMV. Cidofovir was given at the dose of $1 \mathrm{mg} / \mathrm{kg}$ intravenously three times a week instead of a weekly dose given her kidney injury and high creatinine levels. She received probenecid $2 \mathrm{~g}$ orally 1 hour before cidofovir, then 2 hours and 8 hours after the end of infusion to increase cidofovir levels in the blood. For renal protection, she

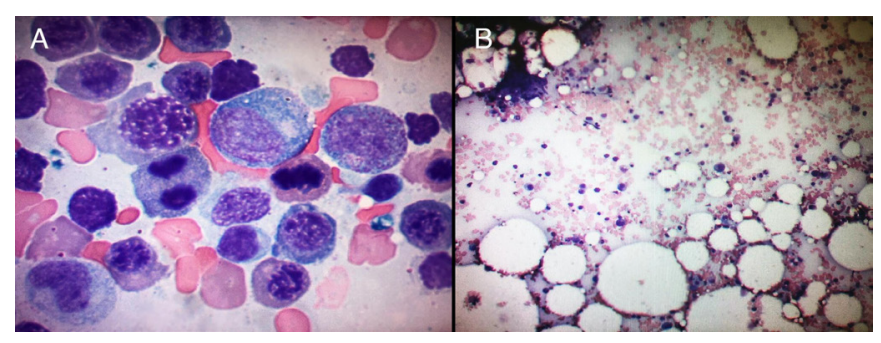

Figure 4 Histology and immunochemistry of bone marrow smear (A) and biopsy (B). Bone marrow biopsy demonstrating hypocellularity. Moderate left shift of the myeloid series and mild left shift of the erythroid series. No lymphocytosis or lymphoma, no definite diagnosis of myelodysplastic syndrome (B). was hydrated with $1 \mathrm{~L}$ of $0.9 \%$ normal saline during cidofovir infusion. Filgrastim (G-CSF) was initiated for her neutropenia, darbepoetin for her anaemia, and intravenous IgG was infused three times at 4-week intervals for her hypogammaglobulinumia.

Neutropenia worsen despite filgrastim, and CMV viral load continued to increase. Due to cidofovir myelotoxicity, a decision was made to focus treatment on CMV infection, while ignoring the $\mathrm{BK}$ and adenovirus. To this end, the patient was changed to ganciclovir $250 \mathrm{mg}$ intravenous two times per day on 23 January 2020 and her urinary symptoms improved for the first time. On 1 February 2020, she was transitioned to oral valganciclovir $450 \mathrm{mg}$ daily and was discharged to home 1 week later, after 101 days in hospital.

\section{OUTCOME AND FOLLOW-UP}

A bone marrow biopsy on 27 January 2020 showed a hypocellular marrow with focal area up to $20 \%-30 \%$ haematopoietic tissue. No evidence of lymphocytosis or lymphoma and no dysplastic changes in morphology were observed. Immunohistochemistry showed $<5 \%$ CD 117 , and was negative for CD20, CD34 and PAX5. The histological appearance represented haematopoietic regeneration post-chemotherapy. On 3 March 2020 follow-up, CMV load was undetectable, adenovirus load was 5000 copies $/ \mathrm{mL}$, BK load was $3.2 \times 10^{8}$ copies $/ \mathrm{mL}$ (table 1 ). She was switched on CMV prophylaxis with resolved haemorrhagic cystitis and received valganciclovir $450 \mathrm{mg}$ p.o. daily for another 3 months and until her absolute lymphocyte count recovers above $10^{9} \mathrm{cells} / \mathrm{L}$. She continued trimethoprim-sulfamethaxole prophylaxis for 6 months post-chemotherapy. Her double-J stents remain in place. While clinically improved, her neutropenia improved on low dose filgrastim until 4 April 2020. Her blood counts normalised 1 month after and she is followed as an outpatient with Haematology, Infectious Diseases, and Urology services at the MUHC.

\section{DISCUSSION}

FCR chemo-immunotherapy is considered the treatment for standard risk CLL patients under the age of $65,{ }^{7}$ with a high overall response rate. However, the predominant complication is myelosuppression. ${ }^{8}$ Persistent neutropenia was reported in $19 \%$ and late infections in $9 \%$ of patients. ${ }^{9}$ The frequency of cytopenias was $35 \%$ at 3 months and $12 \%$ at 9 months after completion of therapy, respectively. Another side effect is prolonged lymphoid immunodeficiency.

Human adenovirus infections usually present as a keratoconjunctivitis or respiratory tract infection. In most healthy individuals the infection is usually self-limited. However, in immunosuppressed patients, infection may disseminate and 
become potentially life-threatening. Disseminated adenovirus infection can result from either de novo infection or a reactivation of clinically silent infection. ${ }^{10}$

BK virus is a member of the polyomavirus family. BK virus reactivation occurs only in immunosuppressed patients and can lead to nephropathy, ureteral stenosis, tubular interstitial damage and haemorrhagic cystitis. Viremia occurs in $20 \%-60 \%$ of this population. There is no specific treatment for BK virus-associated nephropathy, therefore viral replication can only be controlled through modulating the immunosuppressive condition. ${ }^{11}$

CMV is a herpes virus with a large double-stranded DNA that remains latent in the host after primary infection. Immunocompromised patients can have reactivation of their latent infection. Diagnosis of viral reactivation is made through CMV PCR in blood, tissue or body fluid. Manifestations of CMV infection occur most often in the gastrointestinal tract, lungs, liver and retina. ${ }^{12}$ As we did not observe the typical owl's eye tissue lesion in the second bone marrow biopsy, we considered that CMV reactivation was a contributing factor for the pancytopenia, and treatment may have prevented such tissue lesion to develop. First line treatment of CMV infection includes intravenous ganciclovir or its oral prodrug valganciclovir, which are DNA polymerase inhibitors. The major side effect of these drugs is myelosuppression, including neutropenia. ${ }^{4}$

In our patient, the prolonged pancytopenias secondary to FCR was associated with haematuria with an ureteral mass. To date, only two observations on the use of cidofovir to simultaneously treat BK-virus associated haemorrhagic cystitis and CMV reactivation have been reported. However, in the case report by Held et al, the patient had received a bone marrow transplant for chronic myeloid leukaemia, whereas our patient had CLL.

Cidofovir has been suggested in some cases for the treatment of BK virus-associated haemorrhagic cystitis. ${ }^{13}$ Cidofovir and foscarnet are second-line therapies in patients with CMV that are either resistant or refractory to ganciclovir. Cidofovir is a non-cyclic analogue of cytidine monophosphate that terminates CMV DNA synthesis. In vitro studies showed effectiveness against herpes viruses, including CMV, herpes simplex viruses 1 and 2, varicella-zoster, Epstein-Barr virus, human papillomavirus and adenovirus. The main adverse effect is nephrotoxicity, causing proximal tubular injury. Serum creatinine and urine protein measurements are recommended during administration. ${ }^{14}$ Probenecid decreases intratubular secretion and maintains a sufficient plasma concentration to allow for once weekly dosing at $5 \mathrm{mg} / \mathrm{kg}$ to reduce its nephrotoxicity. ${ }^{13}$ An alternate dosing regimen, initially used in our patient, was three times per week dosing at $3 \mathrm{mg} / \mathrm{kg}$. In the study performed by Philippe et $a l$, intravenous cidofovir achieve remission in $81.5 \%$ of the 22 patients. ${ }^{13}$

The patient reported by Held et al recovered fully with cidofovir ${ }^{15}$; however, our patient was switched to ganciclovir due to persistent neutropenia. Bone marrow biopsy was consistent with secondary treatment-related myelosuppression syndrome, without evidence of myelodysplasia or lymphoproliferative infiltration. Myelosuppression is a major side effect of ganciclovir. However, the antiviral effects far outweigh these risks and therefore ganciclovir and its oral prodrug valganciclovir should be considered for patients with pancytopenia secondary to CMV reactivation.

In summary, this unique case of triple-viremia induced haemorrhagic cystitis in an immunosuppressed CLL patient posed both a diagnostic and therapeutic challenge as treatments are nephrotoxic and further increase immunosuppression.
The major learning point is to exercise caution when prescribing FCR chemotherapy on its long-term immunosuppressive effects. It is expected that novel immuno-chemotherapy for CLL should control the disease with reduced immunosuppressive effects. ${ }^{16}$

\section{Patient's perspective}

Translation from French

I was diagnosed with CLL in November 2015. Started the treatments with FCR protocol in April 2019 (six treatments of three consecutive days each). At the end of the fourth treatment, I was not well. I had fever and a large fatigue with no energy. I finished treatments on the 13th of November 2019. On the week of 18 November, the symptoms appeared: fever, incontinent of urine with blood, no appetite, fatigue.

I visited MUHC emergency, 12 hours wait before I had a doctor's room. I stayed the night and the next day I saw the doctor, but they did not know what I had. On the 22nd of November I returned to emergency with a lot of fever and other symptoms. I passed the night in an emergency room. On Saturday they released me, had fever and falls.

On the 24th I returned to emergency, fever and incontinence, etc. I was placed in the corridor in a stretcher with a commode next to the whole world. There was nowhere else for me, I had to go through the doors to go to the public toilet and I urinated every $5 \mathrm{~min}$. I stayed in emergency 5 days before I was admitted to Internal Medicine.

It was a bad experience the three times I was in emergency. On 29 November, I had my own room. I was there till 07 February 2020.

The staff took charge rapidly. There were many tests during this long period to find out the cause of my problems. Everything came from the chemotherapy. Many departments were involved: urology, otolaryngology, haematology, internal medicine, infectious diseases.

There were several healthcare workers who spoke on behalf of other departments.

Very good service with the nursing staffs and the préposé (aux bénéficiaires). On my part, my immune system was severely damaged.

\section{Learning points}

- Infections in immunosuppressed patients remain a diagnostic and therapeutic challenge.

- In patient treated for chronic lymphocytic leukaemia, haematuria can be related to viral infections like BK virus, adenovirus and cytomegalovirus (CMV).

- BK infection is diagnosed with a high index of suspicion, however, combined CMV and adenovirus infections renders the diagnosis more difficult.

- Treatment of these viral infections remains difficult as medications are associated with myelotoxicity (ganciclovir) and renal insufficiency (cidofovir).

Acknowledgements The authors would like to thank Dr Malek Merdad and Dr Isabelle Malhamé for their inspiration to write this article.

Contributors MK and J-PR devised the project, main conceptual ideas and proof outlines. MK took the lead in writing the manuscript the supervision of J-PR. MK created all the images and translated the patient's perspective from French to English. J-PR and JL provided critical feedback and helped shape analysis and manuscript. 
Funding The authors have not declared a specific grant for this research from any funding agency in the public, commercial or not-for-profit sectors.

Competing interests None declared.

Patient consent for publication Obtained.

Provenance and peer review Not commissioned; externally peer reviewed.

Open access This is an open access article distributed in accordance with the Creative Commons Attribution Non Commercial (CC BY-NC 4.0) license, which permits others to distribute, remix, adapt, build upon this work non-commercially, and license their derivative works on different terms, provided the original work is properly cited and the use is non-commercial. See: http://creativecommons.org/ licenses/by-nc/4.0/.

\section{REFERENCES}

1 Lachance S, Christofides AL, Lee JK, et al. A Canadian perspective on the use of immunoglobulin therapy to reduce infectious complications in chronic lymphocytic leukemia. Curr Oncol 2016;23:42-51.

2 Hallek M, Cheson BD, Catovsky D, et al. iwCLL guidelines for diagnosis, indications for treatment, response assessment, and supportive management of CLL. Blood 2018:131:2745-60

3 Molica S. Infections in chronic lymphocytic leukemia: risk factors, and impact on survival, and treatment. Leuk Lymphoma 1994;13:203-14.

4 Ritchie BM, Barreto JN, Barreto EF, et al. Relationship of ganciclovir therapeutic drug monitoring with clinical efficacy and patient safety. Antimicrob Agents Chemother 2019;63:e01855-18.

5 Parikh SA, Leis JF, Chaffee KG, et al. Hypogammaglobulinemia in newly diagnosed chronic lymphocytic leukemia: natural history, clinical correlates, and outcomes. Cancer 2015:121:2883-91.
6 Hallek M, Fischer K, Fingerle-Rowson G, et al. Addition of rituximab to fludarabine and cyclophosphamide in patients with chronic lymphocytic leukaemia: a randomised, open-label, phase 3 trial. Lancet 2010;376:1164-74.

7 Burger JA, Tedeschi A, Barr PM, et al. Ibrutinib as initial therapy for patients with chronic lymphocytic leukemia. N Eng/ I Med 2015;373:2425-37.

8 Strati P. Wierda W, Burger J, et al. Myelosuppression after frontline fludarabine cyclophosphamide, and rituximab in patients with chronic lymphocytic leukemia: analysis of persistent and new-onset cytopenia. Cancer 2013;119:3805-11.

9 Foon KA, Mehta D, Lentzsch S, et al. Long-term results of chemoimmunotherapy with low-dose fludarabine, cyclophosphamide and high-dose rituximab as initial treatment for patients with chronic lymphocytic leukemia. Blood 2012;119:3184-5.

10 Radke JR, Cook JL. Human adenovirus infections: update and consideration of mechanisms of viral persistence. Curr Opin Infect Dis 2018:31:251-6.

11 Alcendor DJ. Bk polyomavirus virus glomerular tropism: implications for virus reactivation from latency and amplification during immunosuppression. J Clin Med 2019;8:1477.

12 Han T-T, Xu L-P, Liu D-H, et al. Cytomegalovirus is a potential risk factor for late-onset hemorrhagic cystitis following allogeneic hematopoietic stem cell transplantation. Am J Hematol 2014:89:55-61.

13 Philippe M, Ranchon F, Gilis L, et al. Cidofovir in the Treatment of BK Virus-Associated Hemorrhagic Cystitis after Allogeneic Hematopoietic Stem Cell Transplantation. Biol Blood Marrow Transplant 2016;22:723-30.

14 El Helou G, Razonable RR. Safety considerations with current and emerging antiviral therapies for cytomegalovirus infection in transplantation. Expert Opin Drug Saf 2019;18:1017-30

15 Held TK, Biel SS, Nitsche A, et al. Treatment of BK virus-associated hemorrhagic cystitis and simultaneous CMV reactivation with cidofovir. Bone Marrow Transplant 2000;26:347-50.

16 lovino L, Shadman M. Novel therapies in chronic lymphocytic leukemia: a rapidly changing landscape. Curr Treat Options Oncol 2020;21:24

Copyright 2020 BMJ Publishing Group. All rights reserved. For permission to reuse any of this content visit https://www.bmj.com/company/products-services/rights-and-licensing/permissions/ BMJ Case Report Fellows may re-use this article for personal use and teaching without any further permission.

Become a Fellow of BMJ Case Reports today and you can:

- Submit as many cases as you like

- Enjoy fast sympathetic peer review and rapid publication of accepted articles

- Access all the published articles

Re-use any of the published material for personal use and teaching without further permission

\section{Customer Service}

If you have any further queries about your subscription, please contact our customer services team on +44 (0) 2071111105 or via email at support@bmj.com.

Visit casereports.bmj.com for more articles like this and to become a Fellow 